\title{
PENGARUH PERAWATAN TALI PUSAT TERBUKA PADA BAYI BARU LAHIR DI PMB MURTINAWITA KOTA PEKANBARU TAHUN 2020
}

\author{
Risa Pitriani, Riska Agustina \\ Program Studi D III Kebidanan STIKes Hang Tuah Pekanbaru
}

\begin{abstract}
The umbilical cord is the channel of life for the fetus while in the womb, it is said to be the channel of life because it is this channel that for 9 months and 10 days supplies nutrients and oxygen to the fetus. When the baby is born this channel is no longer needed, so it must be cut and tied. After the cut, the next step is umbilical cord care. Open umbilical cord care means leaving the umbilical cord open and only cleaning it with clean water, good and correct umbilical cord care will have an impact on the speed of the umbilical cord and reduce the incidence of infection in the umbilical cord. The aim of the case study was to be able to carry out midwifery care for newborns with open umbilical cord care. The method used with the midwifery management approach was then documented in the form of SOAP and comparisons of the umbilical cord from the first day to the puput. This final task was carried out at PMB Murtinawita then continued with home visits to the umbilical cord. The results of the care given by Mrs. $R$ said that she was able to perform umbilical cord care and the umbilical cord looked dry. The results of this case report showed the umbilical cord puput on day 5 without any signs of infection. suggestions are expected to change the method of umbilical cord care to open methods or the latest treatment methods to speed up the umbilical cord puput and reduce the incidence of infection.
\end{abstract}

Keywords: Open umbilical cord care, Newborns, Murtinawita PMB

\begin{abstract}
ABSTRAK
Tali pusat atau umbilical cord adalah saluran kehidupan bagi janin selama di dalam kandungan, dikatakan saluran kehidupan karena saluran inilah yang selama 9 bulan 10 hari menyuplai zat-zat gizi dan oksigen ke janin. saat bayi lahir saluran ini sudah tidak diperlukan lagi, sehingga harus dipotong dan diikat.Setelah dipotong tindakan berikutnya adalah perawatan tali pusat. Perawatan tali pusat terbuka berarti membiarkan tali pusat terbuka dan hanya membersihkannya dengan air bersih, perawatan tali pusat yang baik dan benar akan berdampak pada cepatnya tali pusat puput dan mengurangi kejadian infeksi pada tali pusat. Tujuan studi kasus mampu melaksanakan asuhan kebidanan pada bayi baru lahir dengan perawatan tali pusat terbuka. Metode yang digunakan dengan pendekatan manajemen kebidanan kemudian didokumentasikan dalam bentuk SOAP serta dilakukan perbandingan tali pusat dari hari pertama sampai puput.Tugas akhir ini dilaksanakan di PMB Murtinawita kemudian dilanjutkan dengan kunjungan rumah sampai tali pusat puput. Hasil dariasuhan yang diberikan Ny R mengatakan sudah bisa melakukan perawatan tali pusat dan tali pusat terlihat kering. Hasil laporan kasus ini terlihat tali pusat puput pada hari ke 5 tanpa adanya tanda infeksi. saran diharapkan agar dapat mengganti cara perawatan tali pusat ke metode terbuka atau cara perawatan terbaru untuk mempercepat puputnya tali pusat dan mengurangi kejadian infeksi.
\end{abstract}

Kata Kunci $\quad$ : Perawatan Tali Pusat Terbuka, Bayi Baru Lahir, PMB Murtinawita 


\section{PENDAHULUAN}

Tali pusat atau umbilical cord adalah saluran kehidupan bagi janin selama di dalam kandungan, dikatakan saluran kehidupan karena saluran inilah yang selama 9 bulan 10 hari menyuplai zat-zat gizi dan oksigen ke janin. Tetapi saat bayi lahir, saluran ini sudah tidak diperlukan lagi, sehingga harus dipotong dan diikat atau di jepit.Setelah dipotong tindakan berikutnya adalah perawatan tali pusat yang telah dipotong.Sisa potongan tali pusat pada bayi inilah yang harus dirawat agar tidak terjadi infeksi(Putra, 2012).

Perawatan tali pusat dilakukan untuk mencegah terjadinya infeksi pada bayi baru lahir, upaya ini dilakukan dengan cara menjaga agar luka tersebut tetap bersih, tidak terkena air kencing, kotoran bayi, atau tanah. Banyak pendapat tentang cara terbaik dalam merawat tali pusat agar tidak terjadi peningkatan infeksi,negara-negara yang beriklim tropis perlu mewaspadai penggunaan alkohol yang dahulu populer dan terbukti efektif untuk membersihkan tali pusat, karena sesungguhnya alkohol akan mudah menguap di daerah panas, dengan membiarkan tali pusat mengering, tidak ditutup, dan hanya dibersihkan setiap hari menggunakan air bersih (Marmi \& Rahardjo, 2018).
Perawatan tali pusat terbuka berarti membiarkan tali pusat terbuka dan hanya membersihkannya dengan air bersih, serta membiarkan tali pusat puput dengan sendirinya tanpa membungkus dan membubuhkan daun-daunan, abu dapur, atau ramuan, disini tali pusat hanya dibersihkan dengan menggunakan air bersih lalu dikeringkan dengan kain tanpa ditutup dengan kain kasa(Rukiyah \& Yulianti, 2010).

Dari data SDKI 2017 terlihat adanya penurunan angka kematian bayi menjadi 24/1000 kelahiran hidup. Kematian bayi pada masa neonatal terutama disebabkan oleh tetanus neonatorium dan gangguan perinatal sebagai akibat dari kehamilan resiko tinggi (Profil Anak Indonesia, 2018).

Setelah sikecil lahir, tali pusat yang terhubung dengan ari-ari akan dipotong. Sehingga, tali pusat yang melekat di bagian pusat bayi tersisa sepanjang kurang lebih $4 \mathrm{~cm}$. tali pusat yang telah dipotong segera dijepit, dan akan terlepas sendiri setelah tali pusat benar-benar kering. Dalam keadaan normal, tali pusat akan mengering hingga berubah warna menjadi coklat, dan terlepas dengan sendirinya dalam waktu 7-10 hari. Namun jika terdapat kasus lainnya, hal tersebut bisa berlanjut hingga sampai 2 minggu (Putra, 2012). 
Hasil penelitian (Asiyah et al., 2017) pada metode perawatan tertutup memiliki waktu pelepasan yang lebih lama yaitu 710 hari sedangkan perawatan tali pusat terbuka hanya 5-7 hari.Dari hasil penelitian (Pitriani et al., 2017) perawatan tali pusat terbuka memiliki rata-rata pelepasan tali pusat yang lebih cepat yaitu 6 hari sedangkan perawatan tali pusat tertutup memiliki rata-rata pelepasan tali pusat yang cukup lama yaitu 10 hari.

Serta ditambah penelitian (Reni et al., 2018) rata-rata waktu lepas tali pusat bayi yang dirawat dengan kasa kering atau tertutup adalah 6.55 hari sedangkan waktu lepas tali pusat bayi yang dirawat dengan perawatan terbuka lebih cepat yaitu 5.43 hari.

Dari survey yang dilakukan oleh penulis perawatan tali pusat yang dilakukan di PMB Murtinawita tersebut adalah perawatan tali pusat tertutup, dari survey tersebut didapatkan informasi bahwa pelepasan tali pusat terjadi selama 7-10 hari.

\section{METODE}

Metode yang penulis gunakan yaitu dengan cara melakukan asuhan kebidanan sesuai dengan prosedur yang baik dan benar, meliputi menganjurkan ibu melakukan perawatan tali pusat terbuka pada By Ny "R" umur 23 tahun
P2A0, dilaksanakan di PMB Murtinawita, S.ST kemudian dilanjutkan dengan kunjungan rumah pada tanggal 21-25 Agustus 2020 serta dilakukan perbandingan tali pusat dari hari pertama sampai tali pusat bayi puput. Cara pengumpulan data anamnesa, observasi, pemeriksaan dan dokumentasi. Analisa data dengan membandingkan antara data yang diperoleh dengan teori yang ada.

\section{HASIL}

Kunjungan bayi baru lahir pertama kali dilakukan pada tanggal 21 Agustus 2020

1. Subjektif

Ibu mengatakan ini kelahiran anak ke2, lahir pukul 16. 25 pada saat lahir bayinya menangis kuat pada saat persalinan anak pertam, ibu menggunakan perawatan tali pusat tertutup dan belum mengerti tentang cara perawatan tali pusat terbuka, serta tali pusat bayinya masih basah, tidak bau dan tidak diberi apapun dari sejak lahir.

\section{Objektif}

KU Bayi : Baik TTV :S : 36,7 C, N : $136 \mathrm{x} / \mathrm{m}, \mathrm{P}$ : $44 \mathrm{x} / \mathrm{m}$, Pemeriksaan Fisik Bayi, LK : $35 \mathrm{~cm}, \mathrm{LD}: 34 \mathrm{~cm}$. BB : 2500 gr. PB : $50 \mathrm{~cm}$, Mata: Sklera tidak ikterik, Mulut: reflex menghisap kuat, Leher : tidak ada pembesaran dan pembengkakan 
kelenjar tiroid Dada : simetris, Ekstremitas : jari bayi lengkap, Abdomen : lembek, Punggung : Tidak ada kelainan tulang punggung, Tali pusat : tali pusat masih basah, tali pusat bersih, dan terbungkus kasa, Reflek : Menghisap (sucking) :(+) Menggenggam (graps) : (+)Moro:

(+) Genitalia : Jenis kelamin : laki-laki Testis sudah berada dalam skrotum Anus : (+)

\section{Anamnesis}

Neonatus cukup bulan 1 hari dengan tali pusat masih terbungkus kasa

KU Bayi : Baik

\section{Penatalaksanaan}

a. Memberitahukan ibu hasil pemeriksaan KU Bayi : Baik, TTV : Dalam batas normal, Tidak ada kelainan

b. KIE Perawatan Pada bayi baru lahir, memberitahukan kepada ibu untuk selalu menjaga kebersihan bayinya, menjaga bayi agar tetap kering, melakukan personal hygine saat bayi BAK atau BAB dan membersihkan daerah kemaluan bayi dengan menggunakan kapas basah.

c. KIE tanda-tanda Infeksi Tali Pusat, memberitahukan kepada ibu tanda bahaya infeksi pada tali pusat yaitu : tali pusat kemerahan, tali pusat bengkak, bayi rewel, terasa panas sekitar tali pusat, tali pusat berair atau bernanah jika itu terjadi maka ibu bisa langsung membawa bayinya ke fasilitas kesehatan

d. KIE faktor penyebab lama puputnya tali pusat, ada beberapa faktor yang mempengaruhinya.

e. KIE Perawatan Tali pusat, memberitahu kepada ibu tentang perawatan tali pusat

Kunjungan kedua bayi baru lahir dilakukan pada tanggal 25 Agustus 2020

1. Subjektif

Ibu mengatakan tali pusat bayinya sudah puput

\section{Objektif}

KU Bayi : Baik

TTV : S : 36,7 C, N : 136 x/m, P : 44 $\mathrm{x} / \mathrm{m}$, Tali pusat bayi sudah puput, Tidak ada tanda infeksi.

3. Analisa

Neonatus cukup bulan 5 hari dengan tali pusat sudah puput

KU Bayi : Baik

4. Penatalaksanaan

a. Memberitahukan ibu hasil pemeriksaan

b. KIE Kebersihan Bayi

Memberitahukan ibu untuk selalu menjaga kebersihan bayinya dengan memandikan bayi minimal sehari sekali, serta untuk segera mengganti popok bayi jika 
basah agar tidak terjadi ruam popok.

c. Evaluasi Tali Pusat

Pada perawatan tali pusat terbuka yang dilakukan selama 5 hari didapatkan hasil tali pusat puput pada hari ke 5, tanpa adanya tanda-tanda infeksi.

\section{PEMBAHASAN}

\section{Subjektif}

Berdasarkan kunjungan hari pertamaBy.Ny "R" pada tanggal 21 Agustus 2020 jam 08.30 WIB ibu mengatakan belum mengerti tentang cara perawatan tali pusat, tali pusat masih basah, bersih, tidak berbau serta tidak diberi apapun. Pada kunjungan kelima tanggal 25 Agustus 2020 jam 08. 30 WIB ibu mengatakan tali pusat bayi sudah puput.

Sesuai dengan teori (Putra, 2012) setelah tali pusat bayi dipotong langkah selanjutnya adalah melakukan perawatan pada tali pusat bayi, karena sisa potongan tali pusat yang tidak dirawat akan menyebabkan infeksi.

Dari hasil pemeriksaan yang telah dilakukan selama 5 hari didapat pada kunjungan pertama ibu belum mengerti cara melakukan perawatan tali pusat yang akan mempengaruhi lama puputnya tali pusat sehingga perlunya informasi agar ibu dapat melakukan perawatan tali pusat dengan baik dan benar.

2. Objektif

Dari hasil pemeriksaan kunjungan Berdasarkan kunjungan hari pertama By. Ny "R" pada tanggal 21 Agustus 2020 jam 08.30 WIB didapatkan hasil K/U : Baik, TTV : Dalam batas normal, Tidak ada kelainan, tali pusat masih basah, bersih, dan masih terbungkus kasa. Pada kunjungan kelima tanggal 25 Agustus 2020 jam 08. 30 WIB didapatkan hasil tali pusat sudah puput dan tidak ada tanda infeksi.

Sesuai dengan teori (Sekartini \& Endyarni, 2011) tali pusat yang masih basah perlu dijaga, tali pusat bayi tidak perlu diberi alkohol, obat merah, atau antiseptik.Juga sejalan dengan teori. (Putra, 2012) dalam keaadaan normalnya tali pusat akan mengering hingga berubah warna menjadi coklat, dan terlepas dengan sendirinya dalam waktu 7-10 hari. Namun jika terdapat kasus lainnya, hal tersebut bisa berlanjut hingga 2 minggu.

Tali pusat yang dirawat akan berubah warna dari hari pertama hingga tali pusat bayi puput, perawatan secara terbuka berarti membiarkan tali pusat tanpa menutupnya dengan kasa yang dapat membuat tali pusat lembab serta tidak 
terkena dengan udara luar yang mempengaruhi tali pusat agar cepat kering.

3. Penatalaksanaan

Berdasarkan kunjungan hari pertama didapatkan hasil tali pusat masih basah, bersih, dan tidak diberi apapun.Pada kunjungan kelima didapatkan hasil tali pusat sudah puput dan tidak ada tanda infeksi. Serta ibu dapat melakukan perawatan dengan baik

Sesuai dengan teori (Rukiyah \& Yulianti, 2010) perawatan tali pusat terbuka berarti membiarkan tali pusat terbuka dan hanya membersihkannya dengan air bersih, serta membiarkan tali pusat puput dengan sendirinya tanpa membungkus dan membubuhkan daun-daunan, abu dapur, atau ramuan. Disini tali pusat hanya dibersihkan dengan menggunakan air bersih lalu dikeringkan dengan kain tanpa ditutup dengan kain kasa.

Serta berdasarkan penelitian (Asiyah et al., 2017)pada metode perawatan tertutup memiliki waktu pelepasan yang lebih lama yaitu 7-10 hari sedangkan perawatan tali pusat terbuka hanya 5-7 hari. Dari hasil penelitian (Pitriani et al., 2017) perawatan tali pusat terbuka memiliki rata-rata pelepasan tali pusat yang lebih cepat yaitu 6 hari sedangkan perawatan tali pusat tertutup memiliki rata-rata pelepasan tali pusat yang cukup lama yaitu 10 hari.

Serta ditambah penelitian (Reni et al., 2018)rata-rata waktu lepas tali pusat bayi yang dirawat dengan kasa kering atau tertutup adalah 6.55 hari sedangkan waktu lepas tali pusat bayi yang dirawat dengan perawatan terbuka lebih cepat yaitu 5.43 hari.

Menurut penulis perawatan tali pusat merupakan hal yang sangat sederhana untuk dilakukan karena tali pusat hanya perlu dijaga agar tidak lembab dan basah karena semakin cepat tali pusat bayi kering maka semakin cepat pula tali pusat bayi akan puput untuk menghindari terjadinya infeksi.

\section{KESIMPULAN}

Dari data yang telah dikumpulkan, saat penulis mendapat persetujuan pasien bahwa akan dilakukan asuhan perawatan tali pusat terbuka, analisa yang didapatkan yaitu KU : Baik, dan Tali pusat bayi masih basah serta tidak diberi apapun. Perawatan tali pusat terbuka pada bayi baru lahir normal di PMB Murtinawita dilaksanakan pada tanggal 21-25 Agustus 2020. Penatalaksanaan yang dilakukan yaitu perawatan tali pusat terbuka selama 5 hari, tidak diberi apapun 
dan di hari kelima tali pusat bayi sudah puput, tanpa adanya tanda infeksi

\section{SARAN}

1. Bagi STIKes Hang Tuah Pekanbaru

Diharapkan kedepannya STIKes Hang Tuah dapat menyediakan lebih banyak buku mengenai perawatan tali pusat terbuka serta bisa mengadakan workshop / seminar terbaru tentang perawatan tali pusat pada bayi baru lahir

2. Bagi PMB Murtinawita, SST

Diharapkan kepada penyedia layanan asuhan kebidanan BPM Murtinawita agar dapat mengganti caraperawatan tali pusat dari perawatan yang masih tertutup ke perawatan tali pusat terbuka atau ke cara perawatan tali pusat yang terbaru.

3. Bagi Pelaksana Asuhan Selanjutnya

Diharapkan studi kasus ini dapat dijadikan pedoman atau informasi dan menambah pengetahuan pelaksana asuhan selanjutnya dalam melakukan perawatan tali pusat terbuka guna mempercepat puputnya tali pusat sehingga asuhan ini dapat dilakukan kepada ibu dan bayi lainnya.

\section{DAFTAR PUSTAKA}

Asiyah, N., Islami, \& Mustagfiroh, L. (2017). Perawatan Tali Pusat Terbuka Sebagai Upaya Mempercepat Pelepasan Tali Pusat. Kebidanan, 1 . https://ejr.stikesmuhkudus.ac.id/inde x.php/ijb/article/download/112/175

Marmi, \& Rahardjo, K. (2018). Asuhan Neonatus, Bayi, Balita, dan Anak Prasekolah. PUSTAKA PELAJAR. Profil Anak Indonesia. (2018). https://www.google.com/url?sa=t\&r $\mathrm{ct}=\mathrm{j} \& \mathrm{q}=\&$ esrc $=\mathrm{s} \&$ source $=$ web\&cd $=$ $1 \&$ cad=rja $\&$ uact $=8 \& v e d=2$ ahUKEw j_5ajUmMzoAhXjheYKHbGmBfo QFjAAegQIARAB\&url=https\%3A $\% 2 \mathrm{~F} \% 2 \mathrm{Fwww}$.kemenpppa.go.id\%2 Flib\%2Fuploads\%2Flist\%2F74d38buku-pai2018.pdf\&usg=AOvVaw3Oj7wsy6

FNb8YCuuoOf4Dl

Putra, S. R. (2012). Asuhan Neonatus Bayi dan Balita untuk Keperawatan dan Kebidanan (Rusdianto (Ed.); Pertama,). D-MEDIKA.

Pitriani, R., Damayanti, I. P., \& Afni, R. (2017). Umbilical Cord Care Effectiveness Closed and Open To Release Cord Newborn. Kebidanan, 1 , 1-6. https://www.google.com/url?sa=t\&r $\mathrm{ct}=\mathrm{j} \& \mathrm{q}=\& e s r c=s \&$ source $=$ web\& $\mathrm{cd}=$ 
1\&ved=2ahUKEwi887Lt18zoAhVcI

LcAHSqyAX8QFjAAegQIARAB\&

url=https $\% 3 \mathrm{~A} \% 2 \mathrm{~F} \% 2 \mathrm{Fjournal}$. unive

rsitaspahlawan.ac.id\%2Findex.php\%

2Fdoppler\%2Farticle\%2Fdownload

\%2F139\%2F111\&usg=AOvVaw1_ n2ZxMLMNgw3Xpifjm5WP

Rukiyah, A. Y., \& Yulianti, L. (2010). Asuhan Neonatus Bayi dan Anak Balita (Pertama). CV. Trans Info Medika

Reni, D. P., Nur, F. T., Cahyanto, E. B.,
\& Nugraheni, A. (2018). Perbedaan Perawatan Tali Pusat Terbuka dan Kasa Kering Dengan Lama Pelepasan Tali Pusat Pada Bayi Baru Lahir. Ilmiah Kesehatan Dan Aplikasinya, 6. https://jurnal.uns.ac.id/placentum/art icle/download/22772/16946 